\title{
HORACE LANE: CONSULTOR DA INSTRUÇÃO PÚBLICA PAULISTA E PARTICIPAÇÃO NA EXPOSIÇÃO INTERNACIONAL DE ST. LOUIS (1885-1912)
}

DOI: http://dx.doi.org/10.1590/2236-3459/76330

\author{
Ivanilson Bezerra da Silva' \\ 'Faculdade de Sorocaba (Grupo Universidade Brasil), Sorocaba/SP, Brasil
}

$\cos 80$

\begin{abstract}
Resumo
O artigo analisa a atuação de Horace Manley Lane na instrução pública paulista entre os anos de 1885-1912. Pontuamos que Horace Lane, como consultor da educação pública paulista, foi um dos articuladores da presença de Oscar Thompson e Carlos Reis na Exposição Internacional de St. Louis em 1904. Além disso, acentuamos que a relação entre eles se dava em torno da educação, porém a de Horace Lane e Carlos Reis era fortalecida através da maçonaria. Além dos relatórios encaminhados por Horace Lane aos Trustees nos Estados Unidos, trazemos para a discussão o documento: Education in the State of São Paulo muito pouco conhecido no âmbito da História da Educação, e que representa uma importante fonte, que do nosso ponto de vista, materializa a atuação de Horace Lane como consultor da instrução pública paulista.

Palavras-chave: Horace Lane, Oscar Thompson, Carlos Reis, Exposição de St Louis, instrução pública.
\end{abstract}

\section{HORACE LANE: CONSULTOR DE LA INSTRUCCIÓN PÚBLICA PAULISTA Y PARTICIPACIÓN EN LA EXPOSICIÓN INTERNACIONAL DE ST. LOUIS (1885-1912)}

\begin{abstract}
Resumen
El artículo analiza la actuación de Horace Manley Lane en la instrucción pública paulista entre los años de 1885-1912. En la exposición internacional de St. Louis en 1904, Horace Lane, como consultor de la educación pública paulista, fue uno de los articuladores de la presencia de Oscar Thompson y Carlos Reis en la Exposición Internacional de St. Louis en 1904. Además, acentuamos que la relación entre ellos se daba en torno a la educación, pero la de Horace Lane y Carlos Reis era fortalecida a través de la masonería. Además de los informes enviados por Horace Lane a los Trustees en los Estados Unidos, traemos a la discusión el documento: Education in the State of São Paulo muy poco conocido en el ámbito de la Historia de la Educación, y que representa una importante fuente, que desde nuestro punto de vista, materializa la actuación de Horace Lane como consultor de la instrucción pública paulista.

Palabras clave: Horace Lane, Oscar Thompson, Carlos Reis, Exposición de St Louis, instrucción pública.
\end{abstract}

\section{HORACE LANE: CONSULTANT OF THE SÃO PAULO PUBLIC EDUCATION AND PARTICIPATION IN THE INTERNATIONAL EXHIBITION OF ST. LOUIS (1885-1912)}

\begin{abstract}
The article analyzes the performance of Horace Manley Lane in the public education of São Paulo between the years of 1885-1912. We point out that Horace Lane, as a consultant for public education in São Paulo, was one of the articulators of the presence of Oscar Thompson and Carlos Reis at the St. Louis International
\end{abstract}


Exposition in 1904. In addition, we emphasize that the relationship between them was around education, but that of Horace Lane and Carlos Reis was strengthened through Freemasonry. In addition to the reports forwarded by Horace Lane to the Trustees in the United States, we bring to the discussion the document: Education in the State of São Paulo, very little known in the context of the History of Education, and which represents an important source, which from our point of view, materializes the performance of Horace Lane as consultant of the public education of São Paulo.

Keywords: Horace Lane, Oscar Thompson, Carlos Reis, St Louis Exposition, public instruction.

\section{HORACE LANE: CONSULTANT DE L'ÉDUCATION PUBLIQUE DE SÃO PAULO ET PARTICIPATION À L'EXPOSITION INTERNATIONALE DE SAINT LOUIS (1885-1912)}

\section{Résumé}

L'article analyse la performance de Horace Manley Lane dans l'éducation publique de São Paulo entre les années 1885-1912. Nous soulignons que Horace Lane, en tant que consultant pour l'éducation publique à São Paulo, était l'un des articulateurs de la présence d'Oscar Thompson et de Carlos Reis à l'Exposition internationale de St. Louis en 1904. En outre, nous soulignons que la relation entre eux mais celle d'Horace Lane et de Carlos Reis fut renforcée par la franc-maçonnerie. En plus des rapports transmis par Horace Lane aux Trustees aux États-Unis, nous apportons à la discussion le document: Education dans l'État de São Paulo, très peu connu dans le contexte de l'histoire de l'éducation, et qui représente une source importante, matérialise la performance de Horace Lane en tant que consultant de l'éducation publique de São Paulo. Mots-clés: Horace Lane, Oscar Thompson, Carlos Reis, St Louis Exposition, public instruction. 


\section{Introdução}

$\mathrm{O}$

artigo é parte da nossa tese de doutorado defendida na Faculdade de Educação da Universidade de São Paulo em 2015, intitulada: $A$ figura de Horace Lane: lutas de representações e a formação da rede de Escolas Americanas no Brasil (1885-1912). Mostramos, entre outras coisas, que Horace Lane além de ser o articulador e organizador de uma rede de escolas americanas de confissão de fé presbiteriana no Brasil, atuou como consultor da instrução pública paulista.

A figura de Horace Manley Lane é muito conhecida no campo educacional, porém temos poucos trabalhos que o tomam como objeto de pesquisa. Como presidente da Escola Americana de São Paulo e Mackenzie College estava vinculado à Igreja Presbiteriana norte-americana, devido às disputas de poder em torno da ocupação da presidência do Mackenzie College, liderada por Eduardo Carlos Pereira e seus seguidores. Este procurou desestruturar a liderança de Horace Lane na direção do Mackenzie College e da Escola Americana, desqualificando-o com sendo um homem que não possuía a piedade de um bom cristão. A disputa não era apenas no campo das ideias religiosas, mas era uma tentativa de Eduardo Carlos Pereira chegar à presidência das instituições educacionais supervisionadas por Horace Lane. Apoiado pelos norte-americanos, Lane era mantido como missionário e educador no Brasil, condição que o legitimava no campo presbiteriano brasileiro e conferia as credenciais para ser o presidente da primeira instituição particular e presbiteriana de ensino superior no Brasil. (SILVA, 2015).

Como presidente, a partir do modelo da Escola Americana de São Paulo, adotou como estratégia formar uma rede de escolas americanas no Brasil, principalmente, em cidades que tinham um núcleo de presbiterianos, americanos, maçons ou republicanos ligados à sua pessoa. (SILVA, 2015).

Segundo Léonard (1981) o presbiterianismo desde sua inserção no Brasil, em 1859, encontrou um ambiente favorável para sua expansão, ou seja, as disposições políticas do Imperador e a necessidade que o Brasil tinha de imigrantes. Não faltou apoio para que a nova religião no Brasil se solidificasse em seus propósitos e estratégias. No âmbito político, encontramos Aureliano Cândido Tavares Bastos, deputado que, segundo Vieira (1980), era um grande defensor das causas protestantes. As representações acerca dos americanos e da sua cultura propagadas por Tavares Bastos, Rui Barbosa, Rangel Pestana e outros favoreceram a aproximação entre os missionários protestantes e os políticos que desejam um Brasil Novo. Para Hilsdorf (2009), Tavares Bastos fazia circular nos anos de 1850 e 1860 em seus pronunciamentos políticos a ideia de que a influência americana seria benéfica para a sociedade brasileira. No campo político, os presbiterianos contavam com a simpatia e o apoio de pessoas que viam nessa denominação ideologias favoráveis para a modernização do Brasil. (SILVA, 2010). Porém, esse apoio não era unilateral. Eles se ajudaram mutuamente, a ponto de Horace Lane contribuir com as reformas educacionais do ensino público paulista.

\section{Horace Lane e o ensino público paulista}

Ao atuar como consultor da educação pública paulista, Lane também imprime as marcas da educação norte-americana. Nesse sentido, sua participação na esfera pública reforçava sua atuação como educador, fortalecia sua relação de poder com as elites 
paulistas e reforçava as representações do modelo educacional norte-americano no Brasil.

Na perspectiva da história da educação a participação de Horace Lane no Ensino Público Paulista foi apresentada e discutida inicialmente pela professora Hilsdorf (1977). Para ela, o referido educador Lane representava enquanto diretor uma pessoa sensível aos problemas pedagógicos em sua época. Ele não apenas reconfigurou a instituição escolar fundada pelo casal Chamberlain, mas contribuiu constantemente com as reformas no ensino público paulista. A autora pontua a aceitação das propostas pedagógicas das escolas americanas por parte das elites progressistas. Entre as causas dessa aceitação, pode-se observar, seguindo as análises da autora, que tais escolas proporcionavam um ambiente de respeito aos seus princípios. Embora de origem confessional, elas eram frutos de uma religião que representava progresso para as elites, ou ainda, "ideias mais adiantadas", pois eram ativas, enérgicas, amigas da propaganda e do trabalho. (HILSDORF, 1977, p. 152). Para a autora, tais escolas abririam caminho para as atividades de renovação das mentalidades e das práticas dentro dos quadros pedagógicos e, por extensão, da sociedade brasileira. O segundo motivo pelo qual essas escolas tiveram a boa aceitação das elites progressistas residia no fato de que tal segmento acreditava que o tipo de ensino ministrado em seus espaços era organizado segundo o sistema norte-americano, que vinha há tempos funcionando como um polo de atração para as elites paulistas, por causa da proposta pedagógica e seu caráter democrático.

Ainda segundo a autora, a elite paulista assegurou a maior parte da clientela nas primeiras décadas de organização e proporcionou também adesão dos correligionários, parentes e amigos. Por representar o modelo educacional mais "avançado" para época, logo as elites políticas recorreriam aos educadores norte-americanos em busca de solução para os problemas educacionais do Brasil. Nas palavras de Azevedo (1960), tais escolas representavam o "fermento novo da massa do ensino", por ser o centro de irradiação de atividades renovadas em relação às escolas públicas e privadas.

Os reflexos da iniciativa protestante americana se fizeram sentir no ensino público e particular, decorreram de sua condição de escolas para as vanguardas paulistas. De fato, as experiências renovadoras do ensino particular e as reformas da instrução pública propostas em São Paulo, entre as décadas finais do Império e a primeira década da República, foram, nos seus quadros gerais, iniciativas do mesmo grupo de homens, que, a partir da década de 70 , estava na liderança política e cultural da Província e que, de um modo ou outro, relacionara-se com os colégios americanos de fé protestante existentes em São Paulo. As ligações pessoais dos componentes desse grupo eram antigas; datavam, se não de antes, dos tempos da Academia de Direito de São Paulo. Foram colegas de curso, nos inícios da década de 60, entre outros: Prudente de Morais Barros, Campos Salles, Bernardino de Campos, Rangel Pestana, Salvador Furtado de Mendonça, Francisco Quirino dos Santos e Teófilo Otoni. (HILSDORF, 1977, p. 176).

Seguindo a linha de raciocínio da autora, vários deles tomariam parte da vida política do país, agrupados em torno da bandeira liberal ou da republicana. Ela analisa:

Pertenciam todos eles à geração que encarava o sucesso da República como dependente do tratamento dado ao problema da educação popular. [...] Lutaram esses políticos não apenas pela instauração do regime democrático, mas pela aprovação de projetos educacionais e aceitação, pela sociedade paulista, de escolas renovadas que eles próprios criavam e dirigiam, ou apoiavam. O "Colégio Internacional" e a "Escola Americana", o "Colégio Piracicabano", o "Colégio 
Pestana" e a "Escola Primária Neutralidade" são exemplos de colégios patrocinados pelas vanguardas paulistas. (HILSDORF, 1977, p. 177).

Tal apoio apresentado pela autora foi referendado em trabalho posterior em que afirma:

\begin{abstract}
Mais para o final da década de 80 e no decorrer da década de 90, Horace M. Lane, o novo diretor da Escola Americana terá um papel relevante na implantação das reformas educacional da instrução pública, as quais deveram às escolas americanas de confissão protestante, em muito, sua inspiração e sua execução. M. Guilhermina de Andrade e Miss Marcia Browne que nelas colaboraram, vieram da Escola Americana bem como outros educadores do setor público que se notabilizaram nesse período. Mas, também, muitos integrantes do grupo que se dedicou à renovação econômica, política e cultural de São Paulo na transição Império-República passaram pelos colégios americanos protestantes, desde os seus primeiros momentos, como alunos, docentes e colaboradores. (HILSDORF, 1986, p. 191).
\end{abstract}

A educação no período republicano era o emblema da instauração da nova ordem, o sinal da diferença que se pretendia instituir entre um passado de trevas, obscurantismo e opressão, e um futuro luminoso em que o saber e a cidadania se entrelaçariam trazendo o Progresso. (CARVALHO, 1989). Nesta linha de pensamento, Warde (2004) afirma:

Quatro meses após a Proclamação da República, em março de 1890, teve início a reforma do ensino paulista, marco pelo qual os dirigentes republicanos de São Paulo pretenderam dar visibilidade aos seus lemas e guardar distância do governo central. A presteza com que a reforma foi decretada dá mostras de que as lideranças republicanas que assumiram o governo do Estado de São Paulo estavam de prontidão para começar a república pela educação do povo. Uma educação moderna, guiada por princípios ativos. Pautada no programa de ação elaborado e divulgado por Rangel Pestana nas primeiras páginas do jornal A Província de São Paulo, a reforma de 1890 e seus desdobramentos nos anos subsequentes mostravam claras intenções de fazer das crianças e dos jovens pontos de partida para a gestação de um novo brasileiro, moldado desde o berço por novos comportamentos e habilitado para novas tarefas. Esses traços, ainda que constituídos por meio de referências de variada ordem, dentre as quais se incluíam as europeias e sul-americanas, eram nitidamente constituídos por referência aos Estados Unidos, onde o espírito industrioso se materializava na forma de confiança na ciência e no gosto pelo experimento. (p. 2).

Como representação de um modelo educacional moderno, as escolas americanas chamaram desde as suas origens no Brasil a atenção de personagens ligados ao partido republicano paulista. Entre os representantes do partido republicano estava Rangel Pestana, figura representativa de importante participação política e que ofereceu o apoio necessário para as escolas americanas de confissão protestante. Desde os primeiros anos do Colégio Internacional (1873), Rangel Pestana esteve ligado a essa instituição escolar. Segundo Hilsdorf (1986), ele também estava ligado à figura de Nash Norton e ao pensamento pedagógico que ele representava muito mais do que ao pensamento religioso. Mais tarde, Rangel Pestana se aproximaria de Horace Lane, pois, segundo a autora, Lane representava uma reedição de Nash Norton - figura largamente relacionada nos círculos progressistas da Província, por sua adesão às ideias republicanas, liberais, maçônicas e pelas suas múltiplas representações: médico, negociante, empresário, professor e diretor da Escola Americana de São Paulo e do Mackenzie College.

Para Hilsdorf (1986) foi Lane que apresentou a Rangel Pestana aquelas que seriam 
responsáveis pelos trabalhos de organização das escolas-modelos da rede pública do Estado, criadas pela Reforma de 1890, a professora de pedagogia da Escola Americana, Miss Marcia P. Browne, e sua companheira de trabalho, Maria Guilhermina Loureiro de Andrade ${ }^{1}$. Marcia Browne lecionava Pedagogia no curso Normal da Escola Americana e era antiga conhecida de Rangel Pestana. Maria Guilhermina era graduada pela Normal School of New York. (HILSDORF, 1977). Em trabalho recente, Chamon (2008), corrobora com as análises apontadas por Hilsdorf sobre Lane e as missionárias, dizendo:

Interlocutor dos liberais republicanos de São Paulo, foi Lane quem indicou Maria Guilhermina para trabalhar na Reforma da Instrução Pública paulista em 1890, ao lado de Miss Márcia Brown, educadora muito bem conceituada entre os presbiterianos. Aliás, Maria Guilhermina também gozava de um conceito elevado na visão do diretor da Escola Americana que se referiu a ela, junto a Caetano de Campos, como uma professora de competência sem igual no Brasil. (p. 86).

Para Rangel Pestana, Lane e seus companheiros eram os protótipos dos modernos educadores e foram eles uma das fontes de inspiração e também um dos fatores de realização de seus projetos de melhoria do ensino paulista. (HILSDORF, 1986, p. 209).

Warde (2004) corrobora com Hilsdorf ao afirmar que as lideranças educacionais paulistas utilizaram fartamente das experiências, dos conselhos e do apoio material dos dirigentes das escolas privadas, principalmente, de figuras como Horace Lane, diretor da Escola Americana de São Paulo. Para ela, os missionários norte-americanos foram os mediadores dos padrões norte-americanos para o ensino público paulista. Para Lane, o modelo de educação imperial era arcaico e ultrapassado. (LANE, 1907).

A sua aproximação com os republicanos paulistas, também, vinha ao encontro dos seus próprios interesses educacionais, pois desejava disseminar os valores da cultura e pedagogia norte-americana, não apenas através da Escola Americana e do Mackenzie College, mas também através da sua participação como consultor educacional do governo. Esse papel Ihe garantiu mais projeção e fortaleceu suas relações de poder. Por outro lado, sua participação na reforma do ensino paulista não apenas o projeta nos círculos republicanos, mas também projetava sua instituição de ensino, o Mackenzie College, e reforçava a representação sobre o modelo educacional norte-americano que circulava entre as elites paulistas.

Segundo Hilsdorf (2009):

Pestana e outros simpatizantes puseram em circulação representações sobre as
escolas protestantes americanas que as constituíram como instituições modelares
da pedagogia moderna, diferenciadas por um conjunto de práticas: Sentimento de
liberdade de consciência, de crítica e de discussão. Noções de ordem e hierarquia,
disciplina rígida e altas exigências éticas, baseadas na combinação de obediência
e autogoverno, sem castigos físicos nem morais. Integração entre pensamento e
ação. Atividades extraclasses: música, clubes literários e ligas de temperança.
Organização seriada e progressiva e não sequencial e linear dos estudos.
Conteúdos literários e científicos, trabalho manual como treino para os estudos nos
laboratórios, atletismo, educação física e ginástica sueca. Jardim de infância.
Classes de ensino normal profissionalizante com fundamentação pedagógica em
fisiologia e higiene escolar, ciências naturais, pedagogia e metodologia, filosofia
intelectual e história da educação, e treino prático como regentes de classes (1885).

1 Para um estudo especifico sobre a professora Maria Guilhermina Loureiro de Andrade consultar: Chamon (2005). 
Bibliografia estrangeira, ou produzida e adaptada pelos próprios professores. Ensino bíblico de fundo. Ensino misto, preparando as meninas para "ganhar a vida independentemente" como professoras e missionárias. No lugar da memorização, a utilização das "lições das coisas" e do método intuitivo, apoiado em laboratórios, coleções de espécimes, museus, mapas e cartazes escolares. Método sintético de leitura: palavras a partir das letras e silabas. Caligrafia com modelos e cadernos americanos. Ensino regular e seriado em cursos diurnos e palestras de divulgação noturnas, abertas ao público em geral, como prática da educação popular. Emprego de professoras, inclusive para as matérias científicas, na figura exemplar da professora Marie Rennorte, que dava física, química e ciências naturais no Colégio Piracicabano. (p. 201).

Rangel Pestana colocou em circulação as representações sobre as escolas protestantes americanas, apropriando-se delas como instituições modelares da pedagogia moderna. Diante disso, Santos (2011) pontua que:

\begin{abstract}
A proposta pedagógica que estava sendo instituída na instrução pública e que havia seduzido a todos aqueles que já tinham nutrido algum tipo de contato com ela, era aquela embasada nos pilares do método intuitivo que tinha como progenitores, educadores como Pestalozzi, Froebel. O método em questão largamente experimentado nas escolas públicas da América do Norte estava estabelecido em pilares como 0 ato da observação pormenorizada, do experimento prático, e da indução. Práticas essas que sugeriam desenvolver no aprendiz as devidas condições cognitivas e motoras, competência para desenvolver a autonomia de pensamento e, consequentemente, habilitá-lo para o debate com os mestres e pares. (p. 42).
\end{abstract}

No entender de Rangel Pestana, os professores que foram educados na ótica da escola imperial não teriam condições de ensinar os alunos. (REIS FILHO, 1995). Trazer mestres estrangeiros seria uma possível solução para esse problema. (CARVALHO, 1989). Porém, segundo essa autora, a importação de mestres especializados foi resolvida com a contratação de mestres já radicados no Brasil, mas formados nos Estados Unidos. É o caso, como já mencionamos, das professoras Miss Browne e Maria Guilhermina. Marta Carvalho (1989) ressalta que elas eram exímias na arte de ensinar, porém não tiveram bom êxito na exposição dos princípios que norteavam sua prática aos alunos da Escola Normal.

No dia marcado para o primeiro encontro, os alunos, reunidos numa das salas de aula, as esperavam com grande curiosidade. Depois do toque da sineta, as duas entraram, acompanhadas do Diretor, muito sorridente, a desfazerem-se em mesuras e cortesias. Feita a apresentação, o Dr. Campos retirou-se e D. Maria Guilhermina iniciou sua exposição inaugural. Estava visivelmente intimidada e, talvez por isso, não conseguiu dar a essa exposição a clareza que fora para desejar. Os ouvintes ansiavam por conhecer essas diretrizes na penumbra. Por muito bem informada que se revelasse em processos de ensino, parecia ser dessas pessoas que não sabem elevar-se da noção da árvore à noção da floresta: era dispersiva [...] Miss Browne foi mais feliz: não conhecendo bem a língua, ficou dispensada de falar e mal se aventurou a alguns monossílabos. (RODRIGUES, J. L. apud CARVALHO, 1989, p. 31).

Por outro lado:

Miss Marcia Browne e mais quatro professoras, além do Dr. Horácio Lane, são nomeados para o serviço público do Estado de São Paulo por lei especial, para orientar o seu ensino primário e normal, sendo o Dr. Lane considerado Consultor educacional do Governo. É o modelo da escola Americana que dá origem ao conhecido "Grupo escolar". (AZEVEDO, 1960). 
A projeção de Lane no ensino paulista como consultor educacional do Governo não se deu apenas na segunda metade do século XIX, mas também no início do século XX. No relatório de 1907, encaminhado aos Trustees, Lane afirma que havia sido chamado novamente para revisar os cursos de estudo. Em 1908, falando sobre as condições das escolas públicas no Brasil, afirmava que cada Estado tinha seu próprio sistema. Porém, no Estado de São Paulo, ele era responsável pela forma de organização, e que a educação pública na capital era uma cópia do modelo pedagógico norte-americano. (LANE, 1908). Horace Lane também dava suporte aos reformadores da educação pública paulista através da compra de móveis e de material pedagógico. (HILSDORF, 1977). Os estudos recentes reforçam as ideias levantadas pela autora em 1977, dizendo que Lane e Marcia Browne foram importantes peças na busca pela modernidade educativa, encomendando material pedagógico e móveis dos Estados Unidos. (ALCÂNTARA, 2014). Para a autora, a compra desse material representava o esforço do Estado em se apresentar como incentivador de uma modernidade educativa².

\section{Horace Lane: rede de sociabilidade e sua participação na Exposição de St. Louis com Oscar Thompson e Carlos Reis}

Horace Lane era uma figura bastante atuante no campo educacional paulista o que possibilitou construir uma rede de sociabilidade não apenas com políticos, mas também com outros educadores, tais como Oscar Thompson e Carlos Reis. Podemos constatar isso no artigo publicado na Revista de Ensino (1904) sobre a educação no Estado de São Paulo e do material que seria apresentado na Exposição Internacional de Saint Louis, intitulado: Education in the State of São Paulo. Warde (2002) acentua que nesta Exposição Internacional Oscar Thompson trouxe uma série de livros que se tornaram significativos no contexto da instrução pública paulista. Chama a atenção para o fato de que Thompson era um nome importante nos meios educacionais de São Paulo nas primeiras décadas da República. A autora também destaca as estatísticas educacionais exibidas na Exposição de St. Louis. A produção de tal documento fazia parte do envolvimento das funções que Thompson ocupava enquanto diretor da instrução pública. Porém, a autora entende que o material exposto extrapola em muito as suas gestões, pois está no cerne da construção do Estado Republicano. Além disso, a Exposição Internacional de 1904 é um momento de epifania do progressivismo e do excepcionalismo norte-americanos e que colocava a educação no topo da hierarquia dos temas debatidos no evento.

Porém, Oscar Thompson não foi sozinho à Exposição de St. Louis. O documento intitulado Education in the State of São Paulo é também assinado por Horace Manley Lane e Carlos Reis. Enquanto Oscar Thompson era diretor da Escola Normal de São Paulo e diretor da instrução pública paulista, Carlos Reis era professor titular da cadeira de língua portuguesa. Horace Lane, como sabemos, diretor da Escola Americana e do Mackenzie College. Thompson se afastou do cargo para participar da Exposição Internacional de Saint Louis. Permaneceu no cargo de diretor da Escola Normal até 1920. (WARDE, 2004).

A respeito de Carlos Reis, temos a seguinte afirmação:

\footnotetext{
2 Segundo Alcântara (2014), Horace Lane e Marcia Browne atuaram como mediadores culturais, pois como estrangeiros residentes em São Paulo, envolvidos com a instrução no país de origem e no Brasil, serviram de intermediários entre fornecedores e o governo e que em viagem ao país de origem, fizeram aquisição de material para a escola pública paulista.
} 
O professor Carlos Reis, outro representante na comissão, não é tão conhecido na atualidade, pois seus feitos não circularam tanto quanto os de Thompson. Também foi estudante na Escola Normal quando esta ainda estava instalada na Rua da Boa Morte, atuou como professor primário em escolas do interior no Estado de São Paulo. Obteve o bacharelado em direito na Faculdade de Direito do Largo São Francisco de 1879-1883, como o colega Oscar Thompson. Em 1885 Reis assumiu o posto de segundo delegado da cidade de São Paulo e em 1886 foi eleito vereador. Em 1887 assumiu a cadeira de Língua Portuguesa na Escola Normal e foi também o sócio fundador e primeiro secretário do Instituto Histórico e Geográfico de São Paulo, inclusive é a sua assinatura de secretário a qual encontramos no diploma de membro do Instituto Histórico e Geográfico de Horace Lane. (SANTOS, 2011, p. 84).

Além disso, Carlos Reis era uma figura conhecida nos círculos maçônicos paulista. Foi iniciado em 1876 na Loja Sete de Setembro e filiou-se também na Loja Ordem e Progresso ${ }^{3}$. A referida Loja era muito atuante na educação paulista, mantendo várias escolas. (SILVA, 2010). No período de crise da maçonaria paulista chegou a exercer o cargo de Grão Mestre Estadual interino (A MAÇONARIA NO ESTADO DE SÃO PAULO, setembro de 1931). Horace Lane também era maçom (SILVA, 2015), sua iniciação se deu nos Estados Unidos. Na fonte A Maçonaria no Estado de São Paulo, ele é mencionado duas vezes como irmão, termo usado entre os maçons. Porém não menciona se era membro regular de alguma Loja em São Paulo:

No nosso inolvidável e Poderoso Irmão Dr. Horace M. Lane perde a Maçonaria um dos seus mais belos ornamentos e um legítimo padrão de glória. Melhor do que nos falam as eloquentes manifestações de pesar de todas as classes sociais de São Paulo, pela morte inesperada do glorioso educador da mocidade de nossa pátria. (A MAÇONARIA NO ESTADO DE SÃO PAULO, outubro de 1912, p. 162).

Em relação a Thompson não vimos vestígios nesta fonte a respeito do seu pertencimento à maçonaria. A rede de sociabilidade entre Oscar Thompson, Horace Lane e Carlos Reis se dava em torno da educação e ideias republicanas. Enquanto que Horace Lane e Reis fortaleciam suas relações de poder através da maçonaria, educação, ideais republicanas e do Instituto Histórico e Geográfico de São Paulo.

Conforme Santos (2011):

Os republicanos paulistas, por meio dos seus representantes no Senado Estadual, apresentaram como imperativo organizar e enviar uma equipe que representasse a instrução pública paulista na Exposição Internacional de Saint Louis. Os senadores estaduais definiram e aprovaram uma verba em caráter extraordinário para tal fim como também o voto para a composição da comissão educacional para representar - Estado de São Paulo no campo educacional. Além de propor o envio de uma comitiva, agregaram a proposta de que os membros dessa própria comissão deveriam elaborar um relatório explicativo apresentando de maneira sucinta a condição a qual se encontrava a instrução pública na Província de São Paulo durante o período Imperial. Além disso, deveriam elucidar, e de maneira nada prolixa, as transformações progressistas sofridas por esse departamento após a proclamação da República e a atuação do regime republicano. Essa comitiva de caráter educacional foi constituída excepcionalmente para representar o Estado de

${ }^{3}$ Em nossos trabalhos atuais sobre elite maçônica e educação no Estado de São Paulo elaboramos um quadro prosopográfico dos maçons que alcançaram os maiores graus na maçonaria brasileira e paulista e tiveram posição privilegiada. Entre os membros dessa elite, estão Carlos Reis e Horace Lane. O projeto de pesquisa foi apresentado no programa de Pós-doutorado em Educação da Universidade de São Paulo e tem como supervisor o professor Dr. Bruno Bontempi Júnior. O projeto visa construir uma biografia coletiva dos maçons e analisar a proposta educacional oferta por eles. 
São Paulo estando presente no evento a partir do segundo semestre de 1904. As pessoas nomeadas foram: Oscar Thompson, diretor da Escola Normal de São Paulo; Carlos Reis, professor titular da cadeira de Língua Portuguesa; e também Horace Lane, diretor da Escola Americana e consultor da instrução pública paulista. Um relatório foi preparado pelos três representantes no intuito de ser apresentado e distribuído no decorrer do evento para os participantes da Exposição. (SANTOS, 2011, J. V., p. 81).

Como consultor educacional do governo, Lane estava inteirado dos assuntos relacionados ao ensino público paulista. A presença dele na Exposição de Saint Louis não apenas denotava sua participação na educação pública paulista, como consultor, mas também como um representante dos modelos educacionais desejados por uma parcela da elite republicana. Fontes documentais indicam que Lane dava informações sobre as condições do ensino dos Estados Unidos à Sociedade Beneficente do Professorado Paulista: "Os senhores deveriam ir aos Estados Unidos. Muitos dos problemas que dedicadamente estudam para resolver aqui, lá já se acham em completa execução". (REVISTA DE ENSINO, 1903, p. 193). Nessa mesma revista, o articulista dizia que a Exposição em Saint Louis era o mais importante evento e que seria capaz de recuperar o patriotismo brasileiro.

O documento Education in the State of São Paulo, permite-nos perceber a visão que Lane tinha sobre a educação, juntamente com Oscar Thompson e Carlos Reis. Nele, os três representantes do Brasil mostram internacionalmente o que estava sendo realizado no campo educacional brasileiro. O documento apresentado na Exposição de Saint Louis, pouco discutido na história da educação, possui 64 páginas, e a capa registra os nomes dos três representantes do Brasil supracitados. Nele percebemos as representações que seus atores construíram acerca da instrução pública paulista. Encontramos no documento várias fotos: Dr. Antonio Caetano de Campos, Dr. Cesário Mota, de Miss. Marcia P. Browne, vários grupos escolares, a Biblioteca Pública, o Museu Paulista e o Mackenzie College.

O documento é construído por tópicos que mostram a organização escolar brasileira: Curso Preliminar, Escola Complementar, Escola Normal e Educação Secundária. É também constituído de tópicos que tratam da metodologia, publicações sobre questões educacionais, supervisão das escolas, Educação Superior, Educação Profissional Agrícola, estatísticas escolares. Embora trate da escola pública paulista, o documento também trouxe informações sobre o Mackenzie College e a Escola Americana, instituições protestantes, dirigidas por Horace Lane. Com isso, podemos entender que ele dava a essa instituição visibilidade internacional, além de mostrar que elas estavam de certa forma aliadas às propostas republicanas do Estado de São Paulo. Outras escolas privadas também tiveram espaço, foram as escolas confessionais católicas. Além disso, mostra que a maçonaria deu suporte para a educação paulista com a criação das escolas noturnas ${ }^{4}$.

Vejamos as palavras introdutórias do documento:

Dos 20 estados federados de que se compõe à República dos Estados Unidos do Brasil, São Paulo, situado na região meridional do Brasil, sendo geralmente salubre e dotado de ameníssimo clima. Devido ao espírito adiantado e empreendedor dos seus habitantes, tem o Estado de São Paulo muito prosperado nestes últimos tempos, sendo notável o seu progresso na agricultura, indústria, comércio, artes,

${ }^{4}$ Para um melhor aprofundamento sobre a Maçonaria e educação, consultar: Moraes (2003), Silva (2007), Silva (2009). 
letras, etc. No que respeita a educação popular, objetivo deste memorial, tem o Estado de São Paulo trabalhado esforçadamente no empenho de difundir largamente a instrução e de estabelecer a melhor e mais conveniente organização, pelo que conquistou honrosa posição entre os outros estados da federação brasileira, sustentando competência com aqueles que mais adiantados se acham. A instrução pública em São Paulo foi sempre objeto de zelo e solitude dos poderes públicos, mas só a partir de 1890 é que teve eficaz desenvolvimento. Proclamada a república no Brasil, a 15 de Novembro de 1889, a então província de São Paulo passou, com a denominação de estado federado, a ser dirigida, a princípio por um governador trino provisório, e depois por um governador, sendo escolhido para este posto o eminente estadista Dr. Prudente de Moraes, cujo nome será sempre lembrado com amor e gratidão. Reconhecendo ele que de todos os fatores do progresso e da civilização o mais vital e poderoso é a educação popular, aplicou os seus primeiros cuidados à reforma da escola normal e à criação das escolasmodelos, ponto de partida para os mais elevados cometimentos. Para dirigir aquela e organizar estas, chamou o emérito educacionista Dr. Antonio Caetano de Campos, de pranteada e inolvidável memória. O decreto governamental de 12 de Março de 1890 foi a base da larga e pujante organização do ensino popular que se acha estabelecida em São Paulo. (LANE, THOMPSON, REIS, 1903, p. 3-5).

Os representantes na Exposição de Saint Louis: Carlos Reis, Oscar Thompson e Horace Lane relembram a importância do Estado de São Paulo sobre os demais estados do Brasil e as iniciativas republicanas a respeito da instrução pública. Relembram que para Prudente de Moraes, o principal fator para o progresso e a civilização de uma nação era a educação ${ }^{5}$. Entre as intenções, estava a de apresentar um Estado em pleno desenvolvimento e progresso nas indústrias, agricultura, na educação e no comércio.

Segundo eles, no regime monárquico a instrução pública na Província estava em deplorável estado de abatimento. Porém, somente o período de 1893 a 1895, sob a poderosa vontade, sábia orientação e ilimitada dedicação do preclaro cidadão Dr. Cesário Motta Júnior, que se obteve o mais forte impulso dado à educação popular, do qual se produziram os brilhantes resultados que colhiam naquele momento. Ou seja, eles deixam claro para seus interlocutores, que a educação no Brasil só teve significava melhoria com o advento da República, pois antes permanecia em estado deplorável. Vemos da parte dele, a construção da representação de que o ensino público no período monárquico era deplorável e que no período republicano, ou seja, período em que atuaram como reformadores do ensino público paulista, foi vivenciada a melhoria na instrução pública paulista.

No documento, constroem a seguinte representação de Cesário Mota:

Perfeito homem de governo e verdadeiro democrata, Cesário Motta levantou escolas por toda a parte, tornando-as prazenteiros templos da formosa infância, dignificou o professorado, prestigiando-o e erguendo-o à altura da sua nobre missão, associou-se às festas escolares, rejubilando com as crenças nos seus folguedos infantis. Por isso, Cesário Motta revive em cada escola, em cada professor, em cada aluno, em cada cidadão instruído do Estado de São Paulo; por isso, o seu nome se perpetuará aureolado de glória na história da instrução paulista. (LANE, THOMPSON, REIS, 1903, p. 7).

Os três representantes na Exposição de Saint Louis relembram os benefícios

\footnotetext{
${ }^{5}$ Vale lembrar que Marta Carvalho (1989), ao analisar a educação no período republicano, acentua que o projeto político e educacional republicano era autoritário, pois educar era uma obra de moldagem de um povo, conforme os anseios de Ordem e Progresso de um grupo que se auto investia como elite e com autoridade para promovê-los.
} 
realizados por Cesário Mota em relação à educação, professores, alunos e cidadãos paulistas, destacando a construção de escolas por toda a parte, que para eles eram os símbolos de templos da formosa infância.

Souza (1998) ao analisar a arquitetura das escolas públicas paulistas destaca a importância dessas construções como elemento representativo. Para ela:

\begin{abstract}
Os grupos escolares foram os estabelecimentos de ensino dessa conformação da escola como lugar. Uma arquitetura escolar pública começou a ser gestada nessa época aliando a configuração do espaço às concepções pedagógicas e às finalidades atribuídas à escola primária. Dessa forma, os edifícios dos primeiros grupos escolares puderam sintetizar todo o projeto político atribuído à educação popular: convencer, educar, dar-se a ver! O edifício escolar torna-se portador de uma identificação arquitetônica que o diferenciava dos demais edifícios públicos e civis ao mesmo tempo em que o identificava como um espaço próprio - lugar específico para as atividades de ensino e do trabalho docente. $\mathrm{Na}$ arquitetura escolar encontram-se inscritas, portanto, dimensões simbólicas e pedagógicas. O espaço escolar passa a exercer uma ação educativa dentro e fora dos seus contornos [...] Por entre as salas de aula, corredores, pátios e jardins a criança incorpora uma ética e uma corporeidade inscritas no espaço escolar. (SOUZA, 1998, p. 123).
\end{abstract}

Os expositores em Saint Louis afirmavam que existiam 3320 escolas preliminares para ambos os sexos, sendo 1852 para o masculino, 1348 para o sexo feminino e 120 de ensino misto. Destas, 2504 estavam sob a responsabilidade do Estado e 816 eram mantidas pelos municípios em que estavam situadas. A matrícula nessas escolas totalizava 37.960 alunos. Diziam que existia também na capital do Estado um Jardim de Infância, instalado em 18 de maio de 1896, destinado ao ensino infantil pelo sistema froebeliano. Tinha uma frequência de 180 a 200 crianças, sendo o ensino divido em três períodos e ministrado em quatro classes formadas por crianças de ambos os sexos. Sobre o Grupo Escolar, Lane, Thompson e Reis afirmavam que existiam 58 grupos escolares, sendo 8 na capital e 50 no interior. Os grupos escolares existentes, constituídos pela reunião de escolas das respectivas localidades, tendo, em regra, cinco classes para cada sexo, correspondiam a mais de 580 escolas preliminares, totalizando 39110 alunos matriculados nesses estabelecimentos de ensino. Ao encerar o capítulo relativo à instrução pública do estado de São Paulo, eles relembram o trabalho de Miss Marcia P. Browne:

Cumpre lembrar o nome da operosa colaboradora da grande obra de Caetano de Campos, da ilustre educadora norte-americana Miss Marcia P. Browne e consignarIhe aqui um voto de muita gratidão, um preito de justa homenagem, pelo seu benéfico concurso e dedicados esforços em prol do ensino primário de S. Paulo. Os métodos e processos de ensino adotados nas escolas preliminares, grupos escolares e escolas-modelo são os que ela pôs em prática, primeiro na escolamodelo que tem o nome daquele saudoso mestre, e depois na escola "Prudente de Moraes", de que foi a organizadora. Honra, pois, a Miss Marcia Browne. (LANE, THOMPSON, REIS, 1903, p. 16).

Eles não deixam de mostrar a participação norte-americana na instrução pública paulista. Sabemos muito bem que Lane estava por trás dessas iniciativas educacionais e não deixaria de apresentar em território americano sua participação nas transformações educacionais que o ensino paulista experimentou naquela época. Sobre a gestão da instrução pública em São Paulo, eles afirmavam que tinha o padrão dos Estados Unidos: "Todas as instituições públicas de aprendizagem estão completamente mobiliadas com os 
melhores móveis escolares e materiais disponíveis nos mais avançados países do mundo, mas principalmente nos Estados Unidos da América". (LANE, THOMPSON, REIS, 1903, p. 8). No documento, ainda, afirmam: "Os Inspetores escolares são bem pagos e completamente independentes de influências externas na realização de seu trabalho". (LANE, THOMPSON, REIS, 1903, p. 26). Em documento posterior, encaminhado aos Trustees, Lane vai criticar a atuação dos inspetores de ensino, dizendo que esses pareciam "animais de estimação" dos políticos. (LANE, 1911).

Sobre o material escolar, os representantes na Exposição de Saint Louis afirmavam que:

Todos os estabelecimentos de ensino são dotados dos melhores móveis e modelos de material escolar conhecidos e adotados nas nações cultas, notadamente na América do Norte. A observação e o especial cultivo pedagógico dos professores paulistas têm sido introduzir diversas modificações nesse material, já no sentido de melhorá-lo, já no de adaptá-lo às condições peculiares do ensino no Estado. Atualmente, quase que se não procura fora do Estado o material técnico necessário às escolas; pois os móveis, livros e objetos didáticos, museus escolares, modelos e aparelhos para o ensino são aqui com vantagem fabricados e produzidos. Os edifícios escolares são construídos de acordo com os mais modernos preceitos da higiene e da pedagogia. (LANE, THOMPSON, REIS, 1903, p. 24).

Ao relembrar isso, reforçavam a representação na Exposição que o Brasil seguia o modelo pedagógico norte-americano e de certa forma reforçava o papel de Lane como o consultor da educação pública paulista. Eles afirmam:

O ensino nas escolas de São Paulo é ministrado segundo os processos intuitivos. As lições são empíricas e concretas e encaminhadas de modo que as faculdades dos alunos sejam provocadas a desenvolvimento gradual e harmônico. Principalmente, a faculdade de observação é a que os professores paulistas, de acordo com a pedagogia moderna, mais procuram desenvolver, fazendo os alunos adquirirem pela intuição o conhecimento direto e imediato das coisas. Assim, pelo processo intuitivo é que se inicia a criança no estudo da linguagem, da geografia, da história, da aritmética, das ciências naturais, de todas as disciplinas, enfim, que constituem o programa do ensino primário. (LANE, THOMPSON, REIS, 1903, p. 25).

É interessante que em nenhum momento, eles pontuavam críticas ao governo republicano. Porém, como vimos, Lane nos relatórios aos Trustees tem uma postura bem diferente da adotada na Exposição de Saint Louis. Sobre as escolas particulares, eles afirmavam que existiam várias instituições de ensino particulares. Eles destacam as principais, entre elas o Mackenzie College. Eles apresentam um retrospecto histórico do Mackenzie, desde sua origem até a criação da Faculdade, além dos investimentos efetuados por John Mackenzie. Naquela ocasião, a Escola Americana oferecia escola primária, intermediária e secundária. Tinha 624 alunos matriculados.

A participação de Thompson, Lane e Reis na Exposição de Saint Louis permitiu dar visibilidade às iniciativas republicanas em relação à educação pública paulista, favorecendo a circulação de práticas, representações e apropriações dos modelos pedagógicos norteamericanos em terras brasileiras, reforçando o Estado de São Paulo como um dos mais evoluídos no campo educacional brasileiro. Acreditamos que Lane teve papel importante nessa Exposição, pois como norte-americano tinha as credencias necessárias para conduzir, mediar e ser o interlocutor das duas nações: a brasileira e a norte-americana. 
Provavelmente, tenha sido o principal interlocutor na Exposição de Saint Louis e responsável por influenciar as reformas públicas do ensino paulista. Eles tomaram para si a tarefa de divulgar as práticas pedagógicas e a ações republicanas em relação ao ensino público paulista.

Segundo Marta Carvalho (1998),

Assíduos viajantes, leitores ávidos, os intelectuais que de algum modo tomaram a si a tarefa de remodelar o imaginário e as práticas pedagógicas no país são personagens-chave na elucidação dos processos materiais de produção, circulação e apropriação dos saberes pedagógicos no Brasil. Em um período histórico em que, no país as iniciativas editoriais são escassas, dispersas, descontínuas e, na maior parte dos casos, voluntaristas, a intervenção desses intelectuais não pode ser subestimada. Os crivos que configuram a apropriação que fizeram do que leram, viram, ouviram e vivenciaram na sua privilegiada itinerância por circuitos culturais estranhos à grande maioria das populações brasileiras, foi determinante na configuração de suas estratégias de imposição de modelos pedagógicos. (p. 40).

O pensamento da autora é elucidativo no que diz respeito à circularidade dos modelos pedagógicos. Corroborando com o pensamento da autora, podemos perceber que Lane não somente fez circular o modelo pedagógico norte-americano em terras brasileiras, mas contribuiu para que esse modelo fosse apropriado pelas escolas públicas paulistas. Não faltaram vozes no círculo de relacionamentos pessoais e políticos que construíram representações em torno desse modelo, mostrando que ele era importante para a implantação dos ideais republicanos em relação à educação brasileira.

Segundo Warde (2003):

Oscar Thompson foi o primeiro herdeiro imediato dos primeiros reformadores republicanos. Herdou e intensificou as relações com Horace Lane, que manteve vivo o diálogo da escola pública paulista com a experiência pedagógica presbiteriana, além disso, abriu canais diretos de comunicação de Thompson com os Estados Unidos, tanto em Nova York como em Massachusetts, o que teria facilitado viagens do próprio Thompson como de outros professores do ensino público paulista. ( $p$. 152).

Porém, não faltaram críticas às iniciativas de Oscar Thompson e Lane:

As críticas, entretanto, não ficavam apenas nisso, pois no número seguinte da Revista apareceu o terceiro editorial com o mesmo título e que retomou o problema propondo-se a examiná-lo a partir dos três aspectos que se consideravam essenciais no complexo domínio da educação: os programas de ensino, os métodos de ensino e as aptidões das crianças. Antes de passar a pronunciar-se sobre cada um desses aspectos, o editorialista observava: [...] a própria Inspetoria da Instrução, a terceira das autoridades que, na hierarquia administrativa, superintendem os negócios do ensino- viu que o Dr. Lane e o Dr. Oscar Thompson andaram mal na redação de semelhante programa, agindo impensadamente, ou antes, precipitadamente, sem a reflexão necessária em um trabalho tão sério e de subida indiscutível importância. (CATANI, 1989, p. 150).

Pelo que vemos, Lane não apenas enfrentou as disputas no campo educacional presbiteriano, mas também no campo educacional paulista. Embora mantendo relações de poder com Oscar Thompson, suas iniciativas, em relação ao ensino público paulista, foram criticadas como acentua Catani (1989). Nessa linha de pensamento, José V. Santos (2011) afirma, entre outras coisas, que Augusto Ribeiro de Carvalho, redator e secretário da 
Revista de Ensino foi talvez o articulista com maior ímpeto a criticar a dupla Thompson e Lane. Além disso, José Santos (2011) mostra que aos poucos o nome de Lane some das páginas da Revista de Ensino (1910), o que talvez explique a razão pela qual seu nome também desaparece nesse período das questões relacionadas ao ensino público paulista, ou ainda, enfrentar mais uma demanda em torno da educação poderia ser uma propaganda negativa para seu nome e as instituições que estavam sob sua responsabilidade. Para Hilsdorf (2003),

A proposta republicana partilhava, com as demais, certas tendências da época: ser oferta antecipatória, na medida em que a escola era pensada como uma parte da totalidade, de um projeto político que se antecipava às reivindicações de outros setores da sociedade; ser dualista, pois embora fosse preciso oferecer ensino a toda a sociedade, não se tratava de oferecer todo o ensino para toda a sociedade; ser preocupada com a extensão da escola elementar, reivindicando a alfabetização das massas. (p. 63).

Porém, ao fazer o cruzamento das fontes: documento apresentado na Exposição de Saint Louis com os relatórios encaminhados aos Trustees, vemos uma posição diferente de Lane em relação ao governo brasileiro. Lane, de certa forma, percebia os esforços dos seus companheiros republicanos na questão educacional e expôs em território americano uma visão de como estava a educação no Brasil. Porém, se seguirmos a sua visão sobre a educação do Brasil, após a Exposição de Saint Louis, veremos uma percepção diferente daquela apresentada em solo norte-americano.

No relatório de 1907, Lane não menciona nada acerca da educação pública. Porém, em 1908, dizia aos Trustees que São Paulo era a "Meca" para qual educadores de outros estados se voltavam em busca de inspiração e informação. Nesse ano, segundo Lane, havia um crescimento saudável do sistema de Escolas Públicas e da educação Normal, assim, como no Ensino Superior. Relata que dois superintendentes do Estado foram aos Estados Unidos e voltaram fascinados pelo modelo educacional norte-americano. Em 1909, novamente Lane em breves palavras afirma que cada estado brasileiro tinha seu próprio sistema educacional, e que no estado de São Paulo, ele tinha sido responsável pela organização. No mesmo relatório, ao falar sobre o Ginásio Nacional, afirma que sob as leis da República, o ensino superior estava sob o controle do Governo Federal e que os jovens formados pelo Ginásio Nacional entravam nas escolas profissionais sem exame. As escolas privadas, aprovadas pelo governo, eram submetidas à inspeção e controle do Governo Federal, que mantinha um inspetor residente, com salário de $300 \$ 000$ por mês.

Relembra os Trustees que a lei brasileira proibia o ensino de religião, mas que um secretário da Justiça subserviente, sob pressão do Cardeal, decidiu que as escolas privadas podiam ensinar religião se elas não transgredissem os cursos regulares. Para ele, isso era uma clara evidência da evasão da lei pelos interesses de Roma. No relatório de 1911, informa os Trustees a respeito daquilo que ele chama de "rápida e completa revolução no sistema educacional do país":

O assunto que nos toca mais de perto e que vai interessar mais a vocês é a revolução súbita e completa no sistema educacional do país. Para entender melhor vou aventurar-me em fazer um breve esboço histórico das escolas sob o antigo regime. Sob o Império, a educação era controlada pelo governo central; embora fosse permitido às Províncias gerenciarem as escolas primárias e estritamente em alguns casos, as escolas normais e liceus. Haviam duas escolas de medicina, uma 
na Bahia e uma no Rio; duas escolas de direito, uma no Rio e uma em Ouro Preto. Os seminários teológicos com suas escolas preparatórias, ao passo que o apoio do governo geral, estava sob o controle da Igreja de Roma, assim como as escolas das ordens religiosas. O ensino primário sob o Império era uma farsa e resultou em 1857 em analfabetismo. No advento da República a Igreja foi separada do Estado e suas escolas foram deixados sem apoio. As seis escolas profissionais já mencionados continuaram com pouca mudança e sob o controle direto do governo federal; mas foram autorizadas a criação de escolas profissionais de empresas privadas em condições especiais de fiscalização do Governo, de modo que um grande número de escolas técnicas surgiu nos diferentes estados.

Nos termos da Constituição Federal todo o ensino superior estava sob controle direto do governo central. O "Colégio Pedro Segundo", que sob o império era a única instituição do país que concedia o grau de Bacharel em Artes, na República, foi mudado para "Ginásio Nacional" com um curso de seis anos, equivalente ao estudo desenvolvido até o quarto ano das escolas secundárias americanas, abordando a maior parte das matérias da Escola Superior e conferindo o grau de Bacharel em Ciências e Letras. A lei permitiu a abertura de um número ilimitado de escolas particulares que, em condições especiais tornou-se "Equiparados" ou "igualadas" ao Ginásio Nacional, com o privilégio de conceder diplomas e certificados, que isentam os alunos da prestação de exame para entrarem nas escolas profissionais. Uma das condições que estas escolas devem atender era um depósito de Rs.50:000 $\$ 000$ ou a hipoteca de uma propriedade nesse valor em nome do governo para ficarem sob o controle e inspeção deste. Uma outra condição é o pagamento do salário mensal de Rs.300\$000 por mês para o inspetor indicado pelo governo federal. Uma terceira condição exigia que a escola tivesse laboratórios, recursos materiais e pelo menos 60 alunos matriculados. As principais condições eram facilmente evitadas, mas eram obrigatórias. $O$ inspetor era geralmente um "animal de estimação" do político. Representante direto do Governo Central que possuía "o poder de irritação ilimitado". (LANE, 1911a).

Tratava-se da Lei Rivadávia Correa. Segundo Rocha (2012), além de expressar as regulamentações de ensino, a lei expressava um liberalismo do "livre ensino", que dificultava o surgimento histórico do direito social à educação em sentido moderno. Ela expressava também a desoficialização do ensino público, favoreceu a expansão de escolas públicas e o fim das regulamentações profissionais.

Sobre a questão da estrutura da administração do ensino público no Império, Souza (1998) esclarece:

Havia um inspector geral da Instrução Pública e a fiscalização do ensino era exercida pelas municipalidades que forneciam 0 atestado de frequência aos professores. Por meio de relatórios encaminhados pelos professores diretamente ao inspector geral, este tomava conhecimento do andamento do ensino, das queixas e dos problemas dos professores públicos. (SOUZA 1998, p. 83).

Para ela a estrutura era bem simplificada, enquanto na República estabeleceram novos órgãos administrativos e técnicos para o ensino público: Diretoria Geral de Instrução Pública, Conselho Superior e inspetores de distrito. Lane dizia que tais inspetores eram "animais de estimação" do Governo, ou seja, eram nomeadas pessoas que tinham certo favoritismo.

Ele continua seu relatório, dizendo:

O sistema degenerou em especulação e centenas desses ginásios foram abertos em todo o país. O curso de estudos foi organizado por um " positivista " seguidor de Auguste Comte e era uma confusão; mas, pior que tenha sido, não foi honestamente realizado. Diplomas foram emitidos mediante a prestação de exames. Mesmo os 
estudantes que realizaram todo o curso de forma honesta e fez todo o trabalho, tinham que pagar 15 contos para ingressarem.

Esse sistema educacional tornou-se tão corrupto e tão escandalosamente fora da lei que o Governo aboliu com um simples decreto, proibindo a expedição de Diplomas e a permissão de cada escola profissional organizar seus próprios exames de ingresso. Os Ginásios estaduais estão reorganizando seus cursos de estudo, assim como também os das grandes Ordens Religiosas - todas estas escolas perderam alunos, com a implantação do sistema educacional que no momento foi extinto e algumas escolas chegaram a fechar suas portas. Este sistema corrupto envolveu toda a assim chamada "Educação Superior" do Brasil, exceto algumas escolas alemãs no Sul e o Mackenzie College. As Escolas da Missão Protestante Metodista, Batista, e presbiterianos do Sul dos Estados Unidos, à custa de despesas onerosas, sacrifício de parte de sua Independência e de princípios, entraram para o grupo de "escolas equiparadas", para poderem emitir diplomas e ter seus alunos dispensados dos exames, porém foram abandonadas pelo governo "no frio" e em "má companhia". Muitos alunos protestantes dessas escolas estão buscando o Mackenzie. (LANE, 1911a - tradução nossa).

Para Laguna (1999), Lane fez uma crítica ao governo brasileiro por retirar o apoio às escolas particulares que aceitaram as condições impostas para se equipararem aos Ginásios Nacionais e terem seu funcionamento autorizado legalmente. Em relatório de 1908, percebe-se que Lane não havia aceitado a equiparação de cursos, como fizeram as demais escolas particulares, pois afirma que a sua Instituição de Ensino Superior era a única, dentre as protestantes ou católicas romanas, em todo o Brasil, totalmente independente da supervisão do governo. (LANE, 1908). Em 1909, foi indagado a respeito da razão pela qual não havia feito a equiparação. Respondeu, dizendo que essa sua posição poderia ser reconsiderada no momento em que os cursos do governo e a administração do Ginásio se tornassem razoáveis, de modo a permitirem a execução honesta da lei, e no momento em que toda essa questão ficasse fora do círculo dos "políticos corruptos", de maneira que uma instituição como a que ele administrava pudesse trabalhar em conjunto com a instituição governamental sem risco de perder a dignidade e o respeito próprio. (LANE, 1909). Em 1910, sua posição ainda é mais contundente, quando afirma: "Estamos convictos de que uma instituição protestante não pode aceitar as condições que conferem os privilégios (desejados) ou submeter-se à inspeção do governo sem ficar desacreditada". (LANE, 1910).

Em 1911, Lane afirma que:

A educação primária e Escolas Normais do país estão nas mãos dos Estados e o acompanhamento e desenvolvimento delas variam em cada um dos estados. A educação primária e as Escolas Normais em São Paulo foram organizadas por nós, nos primórdios da República, seguindo o plano geral das escolas públicas de St. Louis, Missouri. O primeiro Jardim de infância (Kindergarten) foi organizado por um ex-aluno da falecida Miss Phebe Thomas. Muitos dos nossos melhores professores foram emprestados para as escolas públicas. Miss Marcia P. Brown, nossa professora de métodos na Escola Americana, foi transferida para o Governo do Estado e organizou o sistema de ensino normal e de treinamento que o Estado de São Paulo possuí hoje. Outros Estados apresentaram pedidos de professores a S. Paulo para reorganizarem suas escolas públicas: Santa Catharina, Sergipe e Mato Grosso estão seguindo as diretrizes educacionais de S. Paulo. No ano passado, estes estados votaram o equivalente a três milhões de dólares para a construção de edifícios escolares públicos. Encontramos escolas primárias em todos os Estados e existem quatro escolas normais. O percentual de analfabetismo diminuiu bastante no Estado de São Paulo, como também nos estados mais prósperos da União. Nos estados do Norte e Centro, a educação é atrasada. Mas o espírito que favorece a educação está se espalhando rapidamente. O fechamento de muitas das 
chamadas Escolas de ensino médio, e a retirada de todos os privilégios especiais das que permaneceram enviou-nos dezenas de estudantes de todo o país e criou uma verdadeira crise na instituição. Nós não atrevemos recusar estes alunos, a "flor da nação", e fazer todo o nosso dever. (1911a - tradução nossa).

Tais medidas, segundo Lane, afetaram a vida de muitas escolas. Algumas fecharam, outras experimentaram o esvaziamento da parte do seu alunado. Diante da crise, Lane afirmava que não recusaria receber os alunos oriundos dessas instituições. Relembra aos Trustees que a educação pública paulista foi influenciada pelo modelo pedagógico da Escola Americana e que outros estados solicitavam o apoio na reorganização do sistema educacional público, tais como: Santa Catarina, Sergipe e Mato Grosso6.

Lane estava atento às mudanças na legislação educacional do seu tempo. Além disso, deixava sempre claro que os problemas educacionais do Brasil eram oriundos do antigo Regime político, a Monarquia. Esse período foi marcado, na sua visão, por muito jogo de interesses e favoritismo à educação católica. Mesmo na época da República, percebia que pessoas eram nomeadas segundo os interesses dos líderes políticos, e que a política brasileira era manchada por muitos "políticos corruptos". Isso afetava diretamente a vida educacional no país, pois havia preferências e clientelismo.

Por outro lado, legitima a representação de que a escola pública paulista recebeu a influência do modelo pedagógico da Escola Americana, mostrando para os Trustees a influência do seu trabalho.

\section{Considerações finais}

Podemos perceber através das fontes e da historiografia que Horace Lane atuou como consultor da instrução pública paulista e construiu durante sua trajetória uma rede de sociabilidade que fortaleceu sua atuação enquanto educador. A sua participação na Exposição de St. Louis, juntamente como Oscar Thompson e Carlos Reis, reforça não apenas a representação como consultor, mas de uma pessoa estratégica que faz circular no seu país de origem (EUA) as representações acerca da educação brasileira. Em nossa ótica, Lane se posiciona nesta exposição com o articular de duas culturas: a brasileira e a norte-americana.

Ao confrontar as fontes, tanto o documento produzido para a Exposição como os relatórios encaminhados aos Trustees nos EUA, percebemos que Horace Lane tinha posturas diferentes em relação a educação no Brasil. $\mathrm{Na}$ primeira fonte, dado a peculiaridade pela qual o documento foi produzido, Horace Lane, Oscar Thompson e Carlos Reis apresentam quadro positivos acerca da educação paulista. Mas, nos seus relatórios aos Trustees, Horace Lane na condição de subordinado, tem como tática, não apenas criticar a educação no Brasil, mas também mostrar a sua atuação como consultor, talvez com o objetivo de conquistar mais apoio para as instituições educacionais sob sua supervisão e de se legitimar diante dos Trustees como um homem influente nos círculos paulistas. Por isso, era importante frisar constantemente que enquanto educador,

\footnotetext{
${ }^{6}$ Não nos foi possível localizar o Plano Geral das Escolas Públicas de St. Louis, Missouri, citado por Horace Lane. Porém tudo leva a crer que Lane faz uma retrospectiva da sua participação nas reformas públicas paulistas nos primeiros anos da República. Ele indicou Miss Browne e Maria Guilhermina L. Andrade para contribuir do ponto de vista pedagógico na reforma educacional iniciada em 1890 por Antônio Caetano de Campos, diretor da Escola Normal de São Paulo. Ajudou também a organizar as Escolas Modelo Caetano de Campos, Luz e do Carmo. Consultar: Souza (1998).
} 
presidente do Mackenzie College, missionário e supervisor da rede de escolas americanas ele tinha a competência de fazer circular entre as elites paulistas o modelo educacional norte-americano.

Como educador e defensor do modelo norte-americano divulgou que esse modelo era superior ao praticado pela "Velha Europa". A divulgação do modelo pedagógico defendido por Lane ganhou adeptos entre os republicanos paulistas, que não somente passaram a divulgar, como também se apropriaram de tal modelo. (HILSDORF, 1986, 2009). Para tanto, serviram-se dos conselhos de Horace Lane para a implantação da proposta pedagógica norte-americana nas escolas públicas paulistas. Para eles, a proposta era a mais moderna e poderia contribuir para a construção de um país mais democrático e modernizado. Ao fabricar suas representações em torno da educação, ele se solidifica como educador no campo religioso, educacional e político. Mas também produz práticas culturais destinadas a moldar certos padrões sociais naqueles que se apropriavam da sua visão educacional, principalmente, os alunos, professores e republicanos ligados a sua rede de sociabilidade. Não faltaram vozes entre os republicanos que difundiram o modelo educacional norte-americano como o mais avançado e moderno.

Para Horace Lane, Oscar Thompson e Carlos Reis a educação era um fator importante para modernizar o país. Apesar de terem posições profissionais diferentes, do ponto de vista ideológico construíram relações de poder para colocarem em prática suas visões educacionais, de acordo com seus interesses pessoais, profissionais e políticos.

\section{Fontes}

GIUSTI, Antonio. A Maçonaria no Estado de São Paulo. Setembro de 1931.

A Maçonaria no Estado de São Paulo. Outubro de 1912.

LANE, Horace Manley; THOMPSON, Oscar; REIS, Carlos. Education in the State of São Paulo. São Paulo: Typographia Brazil de Campos Gurke, 1903.

LANE, Horace Manley. Annual Report Mackenzie College President to the Board of Trustees. 1907. Acervo Histórico da Universidade Presbiteriana Mackenzie.

Annual Report Mackenzie College President to the Board of Trustees. 1908. Acervo Histórico da Universidade Presbiteriana Mackenzie.

Annual Report Mackenzie College President to the Board of Trustees. 1909. Acervo Histórico da Universidade Presbiteriana Mackenzie.

Annual Report Mackenzie College President to the Board of Trustees. 1910. Acervo Histórico da Universidade Presbiteriana Mackenzie.

Annual Report Mackenzie College President to the Board of Trustees. 1911. Acervo Histórico da Universidade Presbiteriana Mackenzie.

Revista de Ensino da Associação Beneficente do Professorado Público de São Paulo. São Paulo, 1902-1933.

\section{Referências}

ALCÂNTARA, Wiara Rosa Rios. Por uma história econômica da escola: a carteira escolar como vetor de relações (São Paulo, 1874-1914). 2014. 339 f. Tese (Doutorado em Educação) - Faculdade de Educação, Universidade de São Paulo, São Paulo, 2014. 
AZEVEDO, Fernando de. Uma interpretação do Instituto Mackenzie. Conferência de Fernando de Azevedo proferida no 90 aniversário do Instituto Mackenzie. O Mackenzie, São Paulo, ano 20, n. 61, dez. 1960.

CARVALHO, Marta Maria Chagas de. A escola e a república. São Paulo: Brasiliense, 1989.

. Por uma história cultural dos saberes pedagógicos. In: SOUSA, Cynthia Pereira de; CATANI, Denice Bárbara (Orgs.). Práticas educativas, culturas escolares, profissão docente. São Paulo: Escrituras. 1998, p. 31-40.

CATANI, Denice Bárbara. Educadores à meia luz: um estudo sobre a Revista de Ensino da Associação Beneficente do professorado público de São Paulo (1902-1918). 1989. 326 f. Tese (Doutorado em Educação) - Faculdade de Educação, Universidade de São Paulo (USP), São Paulo, 1989.

CHAMON, Carla Simone. A trajetória profissional de uma educadora: Maria Guilhermina Loureiro Andrade e a pedagogia norte-americana. História da Educação,

ASPHE/FaE/UFPel, Pelotas, v. 12, n. 24, p. 73-99, jan./abr. 2008.

. Maria Guilhermina Loureiro de Andrade: a trajetória profissional de uma educadora (1864 1914). 2005. Tese (Doutorado em Educação) - Faculdade de Educação, Universidade Federal de Minas Gerais, Belo Horizonte, 2005.

HILSDORF, Maria Lúcia Spedo. Escolas americanas de confissão protestante na província de São Paulo: um estudo de suas origens. 1977. Dissertação (Mestrado em Educação) - Faculdade de Educação, Universidade de São Paulo, São Paulo, 1977.

Francisco Rangel Pestana: jornalista, político, educador. Tese (Doutorado em Educação) - Faculdade de Educação, Universidade de São Paulo, São Paulo, 1986.

História da educação brasileira: Leituras. São Paulo: Pioneira Thompson Learning, 2003.

Revisitando a história das escolas americanas na província de São Paulo. In: BARROS, Gilda Naecia Maciel de (Org). Celso de Rui Beisiegel: professor, administrador e pesquisador. São Paulo: Edusp, 2009. p. 191-205.

Simonton e o panorama religioso do Brasil nos meados do século XIX. In: Simonton, 140 anos de Brasil. São Paulo: Mackenzie, 2000. p. 29-50. (Série Colóquios. v. 3)

LAGUNA, Shirley. Reconstrução histórica do curso normal da Escola Americana de São Paulo,1889-1930. São Paulo: PUC-SP, 1999.

LÉONARD, Émile G. O protestantismo brasileiro: estudo de eclesiologia e de história social. Rio de Janeiro: Juerp, 1981.

MORAES, Carmem Sylvia Vidigal. A socialização da força de trabalho: instrução popular e qualificação profissional no estado de São Paulo (1873-1934). Bragança Paulista: Edusp, 2003. 490 p.

REIS FILHO, Casemiro dos. A educação e a ilusão liberal: origens da escola pública paulista. Campinas: Autores Associados, 1995.

ROCHA, Marlos Bessa Mendes da. A lei brasileira de ensino Rivadávia Corrêa (1911): paradoxo de um certo liberalismo. Educ. rev., Belo Horizonte, v. 28, n. 3, p. 219-239, set. 2012.

SANTOS, José Veloso dos. As contribuições de Horace Lane na instrução pública paulista: (1890-1910). 2011. Dissertação (Mestrado em Educação) - Universidade 
Estadual Paulista, Marília, 2011.

SILVA, Ivanilson Bezerra da. A cidade, a igreja e a escola: relações de poder entre maçons e presbiterianos em Sorocaba na segunda metade do século XIX. 2010. Dissertação (Mestrado em Educação) - Faculdade de Educação, Universidade de São Paulo, São Paulo, 2010.

A figura de Horace Lane: lutas de representações e a formação da rede de escolas americanas no Brasil (1885-1912). 2015. Tese (Doutorado em Educação) Faculdade de Educação, Universidade de São Paulo/USP, São Paulo, 2015.

. Apontamentos sobre maçonaria, abolição e a educação dos filhos de escravos na cidade de Sorocaba no final do século XIX. Histedbr online, n. 27, p. 95-111, 2007. SILVA, Vanderlei da. A participação da Loja Maçônica Perseverança III na educação escolar em Sorocaba: do final do segundo reinado ao final da primeira república. 2009. 108 f. Dissertação (Mestrado em Educação) - Universidade de Sorocaba, Sorocaba, 2009. SOUZA, Rosa Fátima de. Templos de civilização: a implantação da escola primária graduada no estado de São Paulo (1890-1910). São Paulo: Fundação Ed. Unesp, 1998.

VIEIRA, David Gueiros. O protestantismo, a maçonaria e a questão religiosa. Brasília: Universidade de Brasília, 1980.

WARDE, Mirian Jorge. O futuro está nas mãos da psicologia e da pedagogia científica: São Paulo, dos anos dez aos anos trinta do século XX. In: ENCONTRO REGIONAL DE HISTÓRIA - O LUGAR DA HISTÓRIA, 17, 2004. Anpuh/SP-Unicamp. Anais... Campinas: ANPUH, 2004. Cd-rom.

. O itinerário de formação de Lourenço Filho por descomparação. Revista Brasileira de História da Educação, n. 5, p. 125-166, jan./jun. 2003.

Oscar Thompson na Exposição de St. Louis (1904): an exhibit showing "machinery for making machines". In: FREITAS, Marcos Cézar. Os Intelectuais na História da Infância. São Paulo: Cortez, 2002.

IVANILSON BEZERRA DA SILVA é diretor da Faculdade de Sorocaba (Universidade Brasil), doutor em Educação pela Universidade de São Paulo e professor de História do presbiterianismo brasileiro no Seminário Presbiteriano do Sul. Atualmente realiza pósdoutorado em Educação na Universidade de São Paulo, sob a supervisão do professor Dr. Bruno Bontempi Júnior, com o seguinte projeto: Elite maçônica e educação na revista $A$ Maçonaria no Estado de São Paulo (1912-1932).

Endereço: Avenida Padre Joaquim Gonçalves Pacheco, 20, 18051-590, Sorocaba/SP, Brasil.

E-mail: rev.ibs@gmail.com

Recebido em 06 de setembro de 2017.

Aceito em 21 de junho de 2018. 